\title{
ENTRE LA PROPAGANDA Y EL ESPIONAJE: LA DELEGACIÓN ESPECIAL PARA LA INFORMACIÓN DE RESIDENTES EN TERRITORIO LIBERADO (DIDREM) EN LA ESPAÑA DE LA GUERRA CIVIL (1936-1939)*
}

\author{
Dolores Ruiz-Berdún** \\ Alberto Gomis Blanco** \\ Antonio González, Bueno*** \\ Universidad de Alcalá** \\ Universidad Complutense de Madrid***
}

\begin{abstract}
Resumen: Este texto analiza las actividades de la Delegación Especial para la Información de Residentes en Territorio Liberado (DIDREM), una organización en funcionamiento durante los años de la Guerra Civil (1936-1939), conformada por personal voluntario, formalmente destinada a recabar información sobre las personas que se encontraban en Madrid y, con posterioridad, en el resto del territorio sometido por las tropas franquistas y cuyos datos fueron empleados con fines represores, ya durante la guerra y, particularmente, al finalizar ésta.
\end{abstract}

Palabras clave: Guerra Civil, Franquismo, Espionaje, Represión, Acción Católica, DIDREM.

Between publicity and espionage: the Special Delegation for Information of Residents of Liberated Territory (DIDREM) in Spanish Civil War (1936-1939)

Abstract: This article examines the activities of the Special Delegation for Information of Residents of Liberated Territory (DIDREM), an organization operating in the years of the Spanish Civil War (19361939), formed by volunteers, formally intended to gather information on people who were in Madrid and, later, in the rest of the territory subdued by Franco's troops; the data were used with repressive purposes, during the war and, particularly, at the end of it.

Key words: Spanish Civil War, Francoism, Espionage, Repression, Catholic Action, DIDREM.

Data de recepció: 16 de setembre de 2016 / Data d'acceptació: 21 de novembre de 2016.

* Financiado con cargo al proyecto de investigación HAR-2013-42536-P del Ministerio de Economía y Competitividad. Las fuentes documentales empleadas para la realización de este artículo proceden del Archivo General de la Administración (AGA), Archivo Histórico Banco Bilbao-Vizcaya-Argentaria (AHBBVA), Archivo General Militar de Ávila (AGMAV), Archivo General de la Universidad de Navarra (AGUN), Centro Documental de la Memoria Histórica (CDMH) y Biblioteca del Ministerio de la Presidencia (BMP). 


\title{
INTRODUCCIÓN
}

\author{
...Y mientras las armas así hablaron, y la \\ juventud, enardecida combate, en la retaguardia se \\ labora por una nueva España... \\ Francisco Franco, 20/07/1937
}

Son pocos los datos disponibles sobre la participación de los civiles en los mecanismos de información franquistas durante los años de la Guerra Civil española y de la inmediata postguerra (Cenarro, 2002); esta escasez se debe, en parte, a que el interés historiográfico se ha centrado en los resultados de la represión y en sus víctimas, dedicando menos atención a quienes fueron sus artífices; también colaboró a ello la destrucción, en los años sesenta del siglo XX, de documentos pertenecientes a la Delegación Nacional de Información e Investigación de la Falange, lo cual dificulta, aún más, el análisis al respecto (Parejo Fernández, 2011)2.

Nuestro objetivo es abordar el estudio de una de las organizaciones franquistas, establecida durante la Guerra Civil, destinada a la recogida de información: se trata de la Delegación Especial para Información de Residentes en Madrid (DIDREM) que, posteriormente, debido a la evolución de la contienda, se transformaría en la Delegación Especial para Información de Residentes en Territorio Liberado, conservando el acrónimo inicial ${ }^{3}$.

Nuestra fuente primaria fundamental será la memoria relativa al funcionamiento de esta Delegación, elaborada por Manuel Antonio García Alegre ${ }^{4}$ y de la que no se ha localizado ninguna referencia en la producción historiográfica (García Alegre, 1939) ${ }^{5}$. Se une a ella un pequeño fondo documental, generado por el Ministerio de Asuntos Exteriores mientras éste tuvo su sede en Burgos, transferido al AGA en el año 20136 ; un conjunto do-

\footnotetext{
${ }^{1}$ Fragmento del discurso pronunciado por Francisco Franco ante el micrófono de Radio Nacional de España, con motivo del primer aniversario del 18 de julio; recogido en: $A B C$ (Sevilla), 20 de julio de 1937, 3-5, cfr., 4. Con esta misma cita comienza el informe sobre la actuación de la Delegación para la Información de Residentes en Territorio Liberado (DIDREM) ealaborado por Manuel Antonio García Alegre, una de las fuentes fundamentales empleadas en este trabajo: García Alegre, 1939.

${ }^{2}$ Parejo Fernández muestra su perplejidad sobre cómo las delegaciones provinciales de la Falange pudieron procesar, con un número limitado de recursos y personal, una cantidad ingente de fichas y expedientes informativos que fueron cruciales en el engrasado mecanismo represor de la postguerra.

${ }^{3}$ El interés para llevar a cabo esta investigación surgió mientras, uno de nosotros [D.R.B.], investigaba sobre la vida de una matrona catalana exiliada a México: Cinta Font Margalef; gracias a que su hijo, Artur Bladé i Font, proporcionó abundante material de su archivo personal, tuvimos conocimiento de un documento firmado por la DIDREM; la escasa información disponible sobre esta organización motivó nuestro acercamiento al tema.

${ }^{4}$ El nombre de Manuel Antonio García Alegre figura, como responsable de la DIDREM, entre los Jefes de los distintos servicios de Madrid. Columna de Orden y Policía de Ocupación, en un listado elaborado en abril de 1938 (Pérez-Olivares, 2015).

${ }^{5}$ La memoria se conserva en la Biblioteca del Ministerio de la Presidencia, lugar donde ha sido consultada. Agradecemos a Beatriz Martín Rojo, Jefa del Servicio de Biblioteca y Documentación del Ministerio de la Presidencia, las facilidades dadas al respecto.

${ }^{6}$ Este fondo se conserva en una carpeta de tapas duras identificada con la palabra DIDREM [signatura: MECD, AGA, (10) 000 82/02587]; en la localización de este fondo ha colaborado el jefe de sala Daniel Gozalvo Gimeno, a quien agradecemos su ayuda.
} 
cumental que consideramos "pequeño" puesto que, según la Memoria... elaborada en 1939, además de una ingente cantidad de material impreso y manuscrito se generaron alrededor de 1.200.000 fichas en el desarrollo de las funciones de esta Delegación.

\section{LA DELEGACIÓN ESPECIAL PARA INFORMACIÓN DE RESIDENTES EN MADRID}

Nadie duda del rol fundamental que la información adquiere en el desarrollo de cualquier guerra. Las referencias a los servicios de espionaje remiten, en nuestro imaginario colectivo, a un personaje entre siniestro y romántico, con un amplio entrenamiento y capacitación especial para este trabajo (Herrera Hermosilla, 2012); sin embargo, la realidad que relatamos se aleja bastante de esta idea.

En noviembre de 1936 el ejército sublevado pensaba que la entrada de sus tropas en Madrid sería inminente ${ }^{7}$. Surgió entonces la necesidad de obtener una información rápida y precisa sobre los sucesos ocurridos en la capital durante la "dominación marxista". Una de las personas del entorno inmediato de Francisco Franco, José Fariña Ferreño ${ }^{8}$, ideó la denominada Delegación de Información de Residentes en Madrid (DIDREM), con una compleja estructura organizativa (figura 1).

La oficina central de la Delegación se estableció en la Casa de Correos de Valladolid y dependió inicialmente de la "Secretaría General de Su Excelencia el Jefe de Estado" al frente de la cual se encontraba Nicolás Franco; fue éste quien, el 4 de noviembre de 1936, ordenó a José Fariña el inicio de las actividades de la DIDREM:

Siendo inmediata la liberación de la capital de España, y deseando facilitar por cuantos medios sea posible, informes que se soliciten respecto de las personas afectadas por los actuales acontecimientos de Madrid que supongan residiendo allí, he acordado:

Que con mi Delegación especial se encargue de llevar a cabo dicho servicio de información urgente a partir de la toma de Madrid, procurando seguir las normas redactadas a dicho fin por esta Secretaría general.

En el cometido de sus funciones contará usted con el concurso de las Autoridades civiles y militares, las cuales proporcionarán a usted los elementos y auxilios que requiera la misión que se le encomienda por medio de la presente, en servicio de España9

\footnotetext{
${ }^{7}$ El interés por Madrid era tal que incluso Alberto Alcocer ya firmaba su correspondencia durante la guerra como "el alcalde de Madrid" mientras residía en Valladolid: AGMAV, C.42069,6/72. El Alcalde tenía su despacho en el "Círculo de Recreo" de Valladolid (Serrano García, 2005).

8 José Fariña desempeñó este cargo hasta finales de enero de 1938, siendo sustituido por Manuel Antonio García Alegre; ese año, el 30 de noviembre, José Fariña fue ascendido al puesto de Director gerente del Banco de Crédito Local de España, entidad en la que desempeñaba, desde 1925, el cargo de apoderado: AHBBVA, Memorias de Sociedades, Banco de Crédito Local de España, Memorias 1936-1941, 19-24; AHBBVA, Memorias de Sociedades, Banco de Crédito Local de España, Memorias 1968, 13. Agradecemos a Gorka Fuente Barbero y a José Víctor Arroyo Martin el envío de la información relacionada con José Fariña Ferreño conservada en el Archivo Histórico BBVA (Bilbao). En 1961 le fue concedida la Medalla "Al Mérito en el Trabajo", en su categoría de oro, por sus esfuerzos "siempre en línea de servicio y lealtad al Régimen y a los intereses públicos": Decreto 1995/1961 de 13 de octubre, Boletín Oficial del Estado, 24 de octubre de $1961, \mathrm{n}^{\circ} 254,15240$.

${ }^{9}$ La disposición finaliza solicitando que el delegado, José Fariña, informase a Nicolás Franco sobre el cumplimiento e incidencias de lo ordenado. La orden lleva el número de registro de salida 453 (García Alegre, 1939, 49).
} 


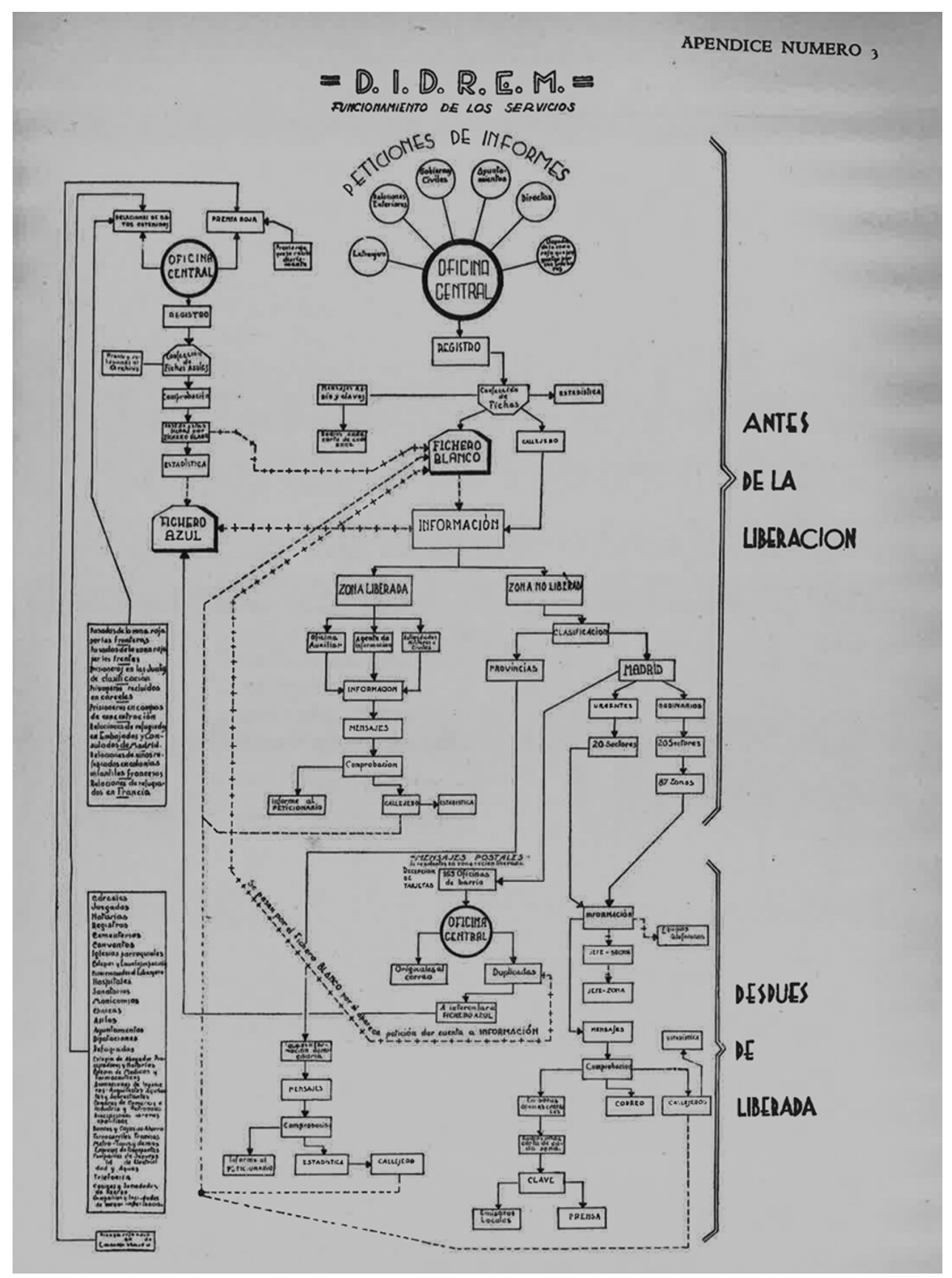

Figura 1. Esquema del funcionamiento de la DIDREM. Fuente: García Alegre, 1939, 52. 
Para informar a la población madrileña sobre este servicio, se redactó un edicto explicando que su función principal consistía en servir de correa de comunicación entre los familiares que habían perdido el contacto a consecuencia de la guerra:

Los Altos Organismos del Estado han establecido un servicio de Información sobre la situación de las personas residentes en Madrid, con el fin de calmar la natural ansiedad de sus familiares y amigos que esperan noticias desde los más apartados rincones de la $\mathrm{Pa}$ tria. Anunciado este servicio breves días antes de liberar Madrid, son millares las peticiones de informe recibidas; más (sic) serán vanos los esfuerzos de esta Delegación para reducir la espera angustiosa, si los llamados a dar noticia de su situación no colaboran en forma eficaz como la que se propone a continuación [...] (García Alegre, 1939, 151).

Eran dos las sugerencias que se ofertaban a quienes quisieran colaborar con esta inquietud: quienes tuvieran conocimiento de que la Delegación les estaba buscando, debían presentarse en una "oficina de barrio" de la Delegación; por otra parte, también se recomendaba que acudiesen a las "oficinas de barrio" las personas que deseasen enviar algún mensaje a los familiares o amigos que residiesen fuera de Madrid.

En el edicto se solicitaba información de todo tipo relativa a personas ausentes o desaparecidas en Madrid en estos primeros meses de la guerra; el escrito finalizaba intentando persuadir a los reacios a colaborar con una acusación implícita: "Sólo los que tengan que ocultarse por algún motivo inconfesable, dejarán de presentarse voluntariamente a colaborar en esta obra".

Como la entrada de las tropas franquistas en Madrid no se hizo efectiva hasta el final de la Guerra, la DIDREM hubo de modificar su estrategia. Los primeros informes se llevaron a cabo en las localidades periféricas del frente madrileño, incluyendo pueblos de las provincias de Toledo y Madrid (García Alegre, 1939, 16). Poco después, los informes se ampliaron a la provincia de Málaga, dado el avance del Ejército Sur sobre la provincia andaluza (Thomas, 1976, 2, 631-637) ${ }^{10}$. Finalmente, una orden emitida por Nicolás Franco, el 31 de marzo de 1937, amplió la jurisdicción de la DIDREM a todo el "territorio liberado":

Teniendo en cuenta que por razón de su eficacia se vienen utilizando los servicios de esta Delegación para obtener informes de las personas residentes en las diversas zonas que se han ido liberando en el territorio nacional por nuestro Glorioso Ejército, sin concretarse a las de Madrid y Málaga a que se refieren las Órdenes de esta Secretaría general de 4 de noviembre de 1936 y 8 de febrero del presente año, y considerando de alta conveniencia que los indicados servicios se organicen y mantengan sin limitación de zonas.

He acordado ampliar la jurisdicción de esa Delegación, creada inicialmente para información de residentes en Madrid, para que actúe en todas las zonas del territorio nacional inmediatamente que se vaya liberando [...] (García Alegre, 1939, 51).

La ampliación jurisdiccional de la DIDREM a todo el territorio ocupado por las tropas franquistas fue recogida por la prensa periódica afín ${ }^{11}$; suman legión los anuncios que re-

10 Para la información concerniente a los residentes en Málaga se organizó una sucursal de la DIDREM en Sevilla, inicialmente en las oficinas del Gobierno Civil de la ciudad: "Servicio de información respecto a los residentes en Málaga", $A B C$ (Sevilla), 12 de febrero de 1937, 13.

11 "Información del Gobierno Civil", Diario de Córdoba (Córdoba), 11 de abril de 1937, 4. 
cordaban, a aquellas personas que solicitasen información, la importancia de mandar "la mayor suma de datos y cantidad de detalles posibles"12.

La DIDREM se convirtió en una fabulosa máquina generadora de información. Sus funciones se ampliaron mucho más allá de lo que había sido su objetivo inicial, no solo en cuanto al territorio sobre el que tenía jurisdicción, también empezó a realizar otro tipo de funciones: recoger información sobre los prisioneros y los "pasados de zona roja” que se encontrasen internados en los campos de concentración, fichar a los "niños evacuados por los rojos a Francia y otros países y sobre los refugiados en territorio francés", obtener datos de personas "a base de la revisión de la prensa roja"13 o por recogida directa en el momento de entrada de las tropas franquistas en las distintas poblaciones. Otro de sus cometidos era establecer enlaces en pueblos y ciudades que se encargasen de transmitir la información en tanto se restablecía el servicio de Correos.

El cambio en la jefatura de la Delegación coincidió con la modificación de la dependencia administrativa de la misma, la cual pasó, en febrero de 1938, a ser función del Ministerio de Orden Público ${ }^{14}$ del primer gobierno franquista constituido el mes anterior ${ }^{15}$. La DIDREM formó parte, desde entonces, de la recién creada Jefatura de Servicios Especiales, al frente de la cual estuvo el militar Fidel de la Cuerda Fernández ${ }^{16}$.

\section{LOS COLABORADORES DE LA DIDREM Y LAS “OFICINAS DE BARRIO”}

Las “oficinas de barrio" eran centros estratégicos donde se recogían las demandas de información; el plan inicial era ubicarlas en todas las iglesias madrileñas, salvo cuando "la barbarie marxista haya destruido o profanado el Templo en forma que impida la utilización para estos fines" (García Alegre, 1939, 151); en este caso, se utilizaría un local próximo, a ser posible una planta baja. El horario de las oficinas quedó establecido de 10:00 a

12 "Los residentes en las poblaciones liberadas", La Prensa (Santa Cruz de Tenerife), 21 de agosto de 1937,4 . Aunque se pedía que se enviase la información a Valladolid, el anuncio partía de Salamanca, lo que demuestra el interés que se tenía en el cuartel general de Franco por este Servicio.

13 La oficina central, en Valladolid, recibía las publicaciones periódicas editadas por los elementos "sospechosos".

14 MECD, AGA, (10) 000 82/02587.

15 Ley organizando la Administración Central del Estado, Boletín Oficial del Estado, 31 de enero de $1938, \mathrm{n}^{\circ} 467,5514-5515$.

${ }^{16}$ Fidel de la Cuerda Fernández había sido nombrado, con fecha de 9 de noviembre de 1937, Secretario de la Jefatura de Interior, Orden Público e Inspección de Fronteras (Boletín Oficial del Estado, 9 de noviembre de 1937, no 385, 4284); el 22 de febrero de 1938, recibió el cargo de Jefe de los Servicios Especiales del Ministerio de Orden Público (Boletín Oficial del Estado, 25 de febrero de 1938, ${ }^{\circ} 492$, 5948), en sustitución de Marcelino de Ulibarri Eguílaz, que había sido su primer responsable desde el 29 de mayo de 1937 (Preston, 2013, 634). Al frente de los Servicios Especiales, Ulibarri inició ya una labor de identificación de personas sospechosas de pertenecer a la masonería hasta que, en febrero de 1938, se hizo cargo de la Oficina de Investigación y Propaganda Anticomunista (OIPA) que continuaría al finalizar la guerra (González Quintana, 1994). Por su parte, Fidel de la Cuerda tuvo una larga trayectoria de empleos durante la dictadura franquista (Jerez Mir, 1982, 255): fue Comisario general de Identificación, desde octubre de 1939 (Boletín Oficial del Estado, 23 de octubre de 1939, n 296, 5930) y, desde 1948, responsable de la puesta en marcha del Documento Nacional de Identidad (Boletín Oficial del Estado, 15 de marzo de 1948, $\mathrm{n}^{\circ}$ 75, 1015; Marín Corbera, 2010, 323-338). Falleció, con rango de General, el 4 de marzo de 1963: "Sepelio del general don Fidel de la Cuerda", ABC (Madrid), 6 de marzo de 1963, 68. 
13:00 horas y de 15:00 a 18:00 horas; éstas permanecían abiertas sólo durante diez días consecutivos, incluyendo los sábados y festivos que hubiese en ese plazo.

Para poder cumplir con los objetivos de la DIDREM se organizó un contingente de colaboradores dispuestos a desplazarse a Madrid en cuanto entrasen en la capital las tropas franquistas. La Delegación tenía dos tipos de colaboradores: unos, de carácter permanente y ámbito general, que actuaban en todo el territorio sometido a las tropas franquistas; otros, los accidentales, quienes reducían su actuación a territorios locales ${ }^{17}$.

Los seleccionados como colaboradores debían firmar un contrato bastante exigente: se les requería un mínimo de diez horas de trabajo diario, no remunerado, y el cumplimiento estricto de las órdenes de sus superiores. Se les advertía de la posibilidad de sufrir una agresión mientras realizaban su cometido o de ser víctimas de las penosas condiciones sanitarias en las que se encontrase la capital de España. También debían comprometerse a su propia manutención, e incluso se pedía que entregasen, por adelantado, un colchón, mantas y ropas de cama que estarían así listas para utilizarse en cuanto se produjese la victoria sobre Madrid (García Alegre, 1939, 163). A los colaboradores permanentes se les entregaba un carnet de identificación (figura 2); el resto usaba brazaletes identificadores.

Alfredo López Martínez (1913-1995), de quien conocemos su vinculación permanente con la DIDREM ${ }^{18}$, responde bien al prototipo de colaborador: un joven que apenas supera la veintena de años, de fuertes convicciones católicas, con formación universitaria, abogado en el caso que nos ocupa, y que muestra una clara adhesión a la causa defendida por Francisco Franco ${ }^{19}$; no muy alejado a éste es el caso de Manuel Aparici Navarro (19021964), presidente nacional de la Juventud de Acción Católica (1934-1941) y fundador de las revistas La Flecha, órgano oficial de la juventud católica (1931-1936) y Signo, semanario nacional de la Juventud de Acción Católica de España (1936-1967) (Silva Tapia, 2007; González Segura, 2008) o el de María de Madariaga y Alonso (1905-2001), presidenta de la Juventud Femenina de Acción Católica (1926-1939) y fundadora de la Hermandad de Enfermeras Católicas "Salus Infirmorum” (Conde Mora, 2008).

Los dirigentes eclesiásticos, al menos los representantes de la Curia madrileña, estuvieron perfectamente informados de las actuaciones de la DIDREM y colaboraron con ella; la correspondencia entre Juan Francisco Morán Ramos (1874-1943), Vicario general de la Diócesis Madrid-Alcalá (1927-1943) y Casimiro Morcillo González (1904-1971), a la sazón

17 En el apéndice 4 de la Memoria... elaborada por García Alegre quedan listados tres tipos de colaboradores: los que trabajaron de un modo permanente ( 75 hombres y una mujer), los que prestaron servicios en las oficinas auxiliares de la Delegación (110 en total, de ellos 21 mujeres), y los colaboradores de Acción Católica, un grupo de 33 miembros, éste mayoritariamente femenino (29 mujeres y 4 hombres) (García Alegre, 1939, 57-63).

18 En el fondo "Alfredo López Martínez" del Archivo General de la Universidad de Navarra (ES.31201.AGUN/2, signatura: caja 1, documento 112) se conserva su carnet de colaborador de la DIDREM, éste lleva el número de registro 114; no obstante, su nombre no aparece recogido en la Memoria... de la organización fechada en 1939, lo cual no es de extrañar; tan solo conocemos 219 personas (apéndice 4) de los 625 colaboradores (apéndice 5) con que contó la DIDREM: 300 de ellos en Madrid, los otros 325 en otras localidades: García Alegre, 1939, 57-65. Agradecemos a Marian Zabala su ayuda para la consulta de los fondos conservados en el Archivo General de la Universidad de Navarra.

19 Alfredo López Martínez fue presidente de la Junta Nacional de Acción Católica (1945-1959); desde 1931 a 1964 ejerció la profesión de abogado; durante el franquismo ocupó un sillón como procurador en Cortes (1958-1964) y el cargo de Subsecretario del Ministerio de Justicia (1965-1973): ABC (Madrid), 1 de enero de $1995,59$. 

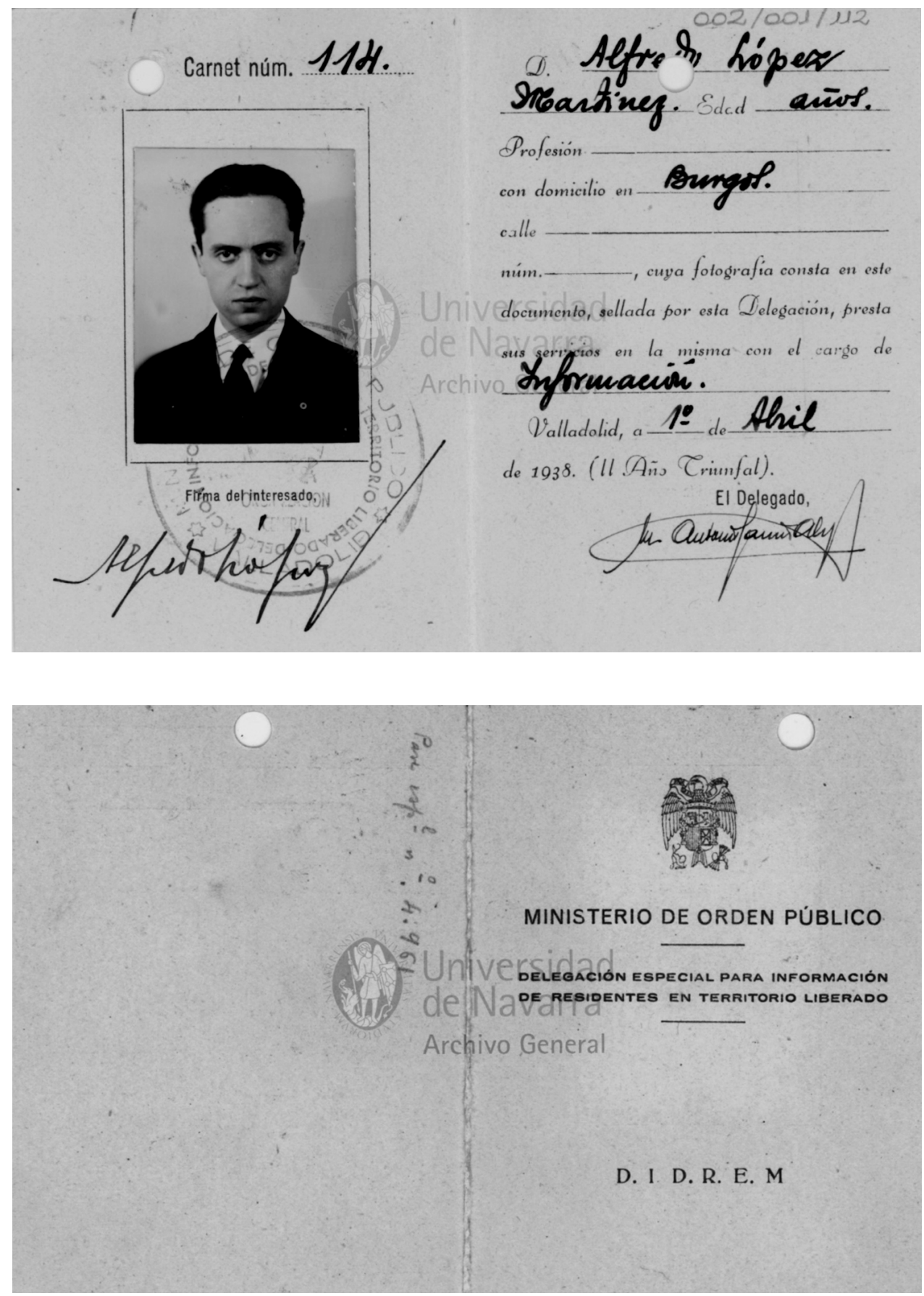

Figura 2. Anverso y reverso del carnet de colaborador de DIDREM perteneciente a Alfredo López Martínez (1913-1995). Fuente: ES.31201.AGUN/2, signatura: caja 1, documento 112. 
profesor en el Seminario de Madrid y Consiliario nacional de las Mujeres de Acción Católica, férreo reorganizador de la Diócesis madrileña en los tiempos de la Guerra, incluyen algunas notas relativas a esta colaboración entre Casimiro Morcillo y la DIDREM.

Fue el propio Leopoldo Eijo Garay (1878-1963), obispo de Madrid-Alcalá, quien realizó las gestiones ante las autoridades del Gobierno Militar de Burgos, para que, con las primeras tropas que entrasen en Madrid, lo hiciesen algunos de sus colaboradores más próximos. En una carta que Eijo Garay dirige a Morán, fechada el 25 de noviembre de 1936, alude a las negociaciones con José Fariña Ferreño para que se agregasen a la DIDREM tanto Casimiro Morcillo como su capellán, Eugenio Pascual: “Así al menos tendríamos allí desde el primer instante personas que se ocupasen del clero que haya en Madrid, de las iglesias, etc. Podrían distribuirlos por las Iglesia, limpiar y reconciliar éstas, y empezar cuanto antes la celebración de Misas y administración de Sacramentos"20. El trabajo de Casimiro Morcillo en la sede central de la Delegación debió de ser bastante activo; en mayo de 1937, Morán escribirá a Morcillo: “...A ver el giro que llevaban las cosas de Bilbao, supuse que vendría U. por aquí; pero por lo visto la Didrem le retiene en Valladolid. Lo siento" (Alfaya Camacho, 1988, 544). Sabemos también, por carta del vicario Morán, fechada el 18 de mayo de 1937, de la estancia de Casimiro Morcillo, en Valladolid, plenamente incorporado a la DIDREM (Alfaya Camacho, 1988, 563).

La participación de las mujeres leales al ejército franquista en las labores de información durante la Guerra Civil queda patente en una carta remitida por María de Cárdenas a Mercedes Milá Noya, a la sazón Inspectora General del personal femenino de hospitales franquistas (Ruiz-Berdún, 2015, 523-530), fechada el 10 de febrero de 1939:

Querida Mercedes [...] Cuanto agradecería pudieras conseguirme un salvoconducto para cuando llegue el momento de entrar en Madrid, pues aunque soy la Delegada de Frentes y Hospitales en esta localidad [Fuenterrabía] y me tenían ofrecida la entrada en la capital, me temo que pase lo mismo que en Barcelona.

Tengo interés en entrar pronto por varios motivos, el primero para ayudar sobre todo en organizaciones de información, pues tú sabes muy bien lo mucho que me he ocupado de esto, y mi actitud y conocimientos en ficheros, etc. y como conozco el Barrio de Salamanca [...] Confío en ti que me lo puedas conseguir y ya sabes que cuando me ofrezco a trabajar cumplo a lo que me comprometo ${ }^{21}$.

La carta se remitía desde Fuenterrabía, lugar donde estuvo establecida una oficina de la DIDREM, que contó con bastantes colaboradores, aunque el nombre de María de Cárdenas no figura en la Memoria... redactada en $1939^{22}$. Sin embargo, como se ha visto, tampoco figuraba en el documento Alfredo López Martínez, poseedor de uno de los carnets de informador de la organización.

Sin lugar a dudas, la mujer que mayor influencia tuvo en las actividades de la DIDREM fue María de la Concepción Sanchiz Calatayud, miembro del Consejo Superior de la Con-

${ }^{20}$ Para la que se presumía como pronta entrada en Madrid, nuestros protagonistas ya habían conseguido los correspondientes permisos: Moran "un salvoconducto azul firmado por Mola (...) y Morcillo y D. Eugenio Pascual lo harán a través de la DIDREM” (Alfaya Camacho, 1988, 544).

21 AGMAV, C. 42069, 6 /86-88.

22 Sin embargo, sí queda adscrita a la oficina de Fuenterrabía Esperanza García Alegre, hermana del autor de la Memoria... (García Alegre, 1939, 60-61). 
federación de las Mujeres Católicas ${ }^{23}$; ella era la encargada de seleccionar a las posibles colaboradoras "a labor tan humanitaria" de entre las filas de la Confederación (García Alegre, 1939, 159). Estas labores de información realizadas por las mujeres de Acción Católica demostrarían que no solo se dedicaron durante la guerra al cuidado de la infancia o de personas enfermas (Moreno Seco, 2003), si bien los lugares en los que obtenían dicha información (hospitales, escuelas, asilos... ver tabla 1) eran considerados una prolongación del ámbito doméstico y, por lo tanto, un aceptable espacio de socialización femenina, por lo que podrían pasar más desapercibidas.

Además de colaborar con su esfuerzo, algunas personas ofrecieron enseres que pudiesen facilitar el trabajo de la Delegación: desde muebles a automóviles, pasando por lo que, probablemente, fuese uno de los objetos más preciados: las emisoras de radio de onda corta ${ }^{24}$.

La DIDREM dispuso de cuatro emisoras que funcionaron de manera constante: tres de ellas pertenecieron a otros tantos colaboradores, la cuarta fue requisada por la Falange en la finca de San Rafael (Segovia), que fuera propiedad de Alejandro Lerroux García (18641949), presidente del Partido Republicano Radical (PRR) (García Alegre, 1939, 19). La estación número 1 era propiedad de Ángel Pereira Renda, radioaficionado, comandante del Ejército franquista, natural de La Estrada (Pontevedra) (Blanco Valdés, 2003, 110-119); su estación de onda corta fue vital para la comunicación de los militares del ejército franquista en el Nordeste de España con Madrid, donde llegaban los mensajes a través de la Cruz Roja Internacional ${ }^{25}$. La estación de onda corta número 2 era propiedad del también gallego Agustín Folla Leis, profesor de Ciencias Naturales en el Instituto de Betanzos y que, lógicamente, obtuvo la depuración favorable en la postguerra (Negrín Fajardo, 2006, 59-99). La estación número 3 pertenecía a Martín Hernández González quien, poco antes de iniciarse la contienda, había publicado en Valladolid un Manual del Radioescucha (Hernández González, 1935).

Estas estaciones actuaban, al servicio de la Delegación, como elementos transmisores de los mensajes informantes sobre la situación de los residentes, primero en Madrid, y después en otros lugares. Junto a ellas, la DIDREM dispuso de una serie de estaciones colaboradoras de onda extracorta, las cuales se encargaban de la recepción de los mensajes que la Delegación dirigía, utilizando sus estaciones transmisoras; así queda recogido en el telegrama que se envía, el 10 de junio de 1938, desde la Delegación en Valladolid a la Estación de Radio EA7-CO de Sevilla, donde se indica:

Figurando su emisora de radio en la lista de las corresponsales, para efectuar el servicio de mensajes de información con las emisoras de esta delegación, ruego a Vd. tenga la bondad de manifestar si su estación sigue autorizada para efectuar dicho servicio ${ }^{26}$.

${ }^{23}$ Dada la necesidad de reorganizar el Consejo Superior de la Confederación de las Mujeres Católicas con miembros que estuviesen residiendo en "territorio liberado", en febrero de 1937 fue elegida vicepresidenta de propaganda de dicho Consejo (Andrés-Gallego y Pazos (eds.), 2002, vol. 3: 31).

${ }^{24}$ La localización, incautación y control de las emisoras de radio fue crucial, para ambos ejércitos, durante el conflicto bélico (Cervera Gil, 1998, 263-293).

${ }^{25}$ Fernández Castro (2004), 229-333. En la primera imagen del artículo (232), aparece Ángel Pereira Renda fotografiado junto a su emisora de onda corta modelo EAJ-BS.

26 Archivo particular [AGB]. 
Tabla 1. Grupos de establecimientos donde los agentes de DIDREM debían obtener sus informes. Elaboración propia a partir de García Alegre, 1939, 27-29.

\begin{tabular}{|c|c|c|}
\hline Grupo & Establecimientos & Equipo de informadores \\
\hline $1^{\circ}$ & $\begin{array}{l}\text { 1.- Juzgados } \\
\text { 2.- Cárceles } \\
\text { 3.- Registros } \\
\text { 4.- Cementerios } \\
\end{array}$ & Masculino \\
\hline $2^{\circ}$ & $\begin{array}{l}\text { 5.- Cuarteles } \\
\text { 6.- Centros oficiales, políticos o militares } \\
\text { 7.- Asociaciones políticas y obreras }\end{array}$ & Masculino \\
\hline $3^{\circ}$ & $\begin{array}{l}\text { 8.- Asilos } \\
\text { 9.- Hospitales } \\
\text { 10.- Sanatorios } \\
\text { 11.- Manicomios } \\
\text { 12.- Clínicas } \\
\end{array}$ & Femenino \\
\hline $4^{\circ}$ & $\begin{array}{l}\text { 13.- Iglesias parroquiales } \\
\text { 14.- Conventos }\end{array}$ & Femenino \\
\hline $5^{\circ}$ & 15.- Colegios y escuelas especiales & Femenino \\
\hline $6^{\circ}$ & $\begin{array}{l}\text { 16.- Ayuntamientos } \\
\text { 17.- Refugiados } \\
\text { 18.- Embajadas, legaciones y consulados }\end{array}$ & Masculino \\
\hline $7^{\circ}$ & $\begin{array}{l}\text { 19.- Colegios de abogados, etc. } \\
\text { 20.- Notarias } \\
\text { 21.- Colegios de médicos y farmacéuticos } \\
\text { 22.- Asociaciones profesionales: ingenieros, arquitectos, } \\
\text { ayudantes, sobresantes, etc. } \\
\text { 23.- Cámaras Oficiales de Comercio e Industria; Patronales } \\
\text { 24.- Bancos, cajas de ahorro y demás institutos de crédito } \\
\text { 25.- Ferrocarriles, tranvías, metro, taxis y demás empresas de } \\
\text { transporte } \\
\text { 26.- Compañías de electricidad y aguas } \\
\text { 27.- Compañías de seguros } \\
\text { 28.- Telefónica } \\
\text { 29.- Casinos y sociedades de recreo } \\
\text { 30.- Compañías y sociedades }\end{array}$ & $\begin{array}{l}\text { Dirigidos por la propia oficina } \\
\text { central de la DIDREM a través de } \\
\text { las autoridades locales, militares y } \\
\text { civiles. En muchas ocasiones se } \\
\text { encomendaba a las propias } \\
\text { asociaciones la obtención de los } \\
\text { informes }\end{array}$ \\
\hline $8^{\circ}$ & 31.- Diarios y publicaciones & Masculino \\
\hline
\end{tabular}

Otro elemento fundamental para el funcionamiento del servicio fue contar con medios de locomoción que permitiesen un traslado ágil de las informaciones y la comunicación entre las diferentes oficinas de la Delegación. Los parques automovilísticos que el ejército franquista disponía en Salamanca, Córdoba y Valladolid aportaron nueve vehículos; además, se requisaron una veintena de coches particulares ${ }^{27}$, devueltos a sus propietarios al finalizar la contienda; algunos pertenecieron a los propios colaboradores de la Delegación ${ }^{28}$.

27 Los datos disponibles no permiten conocer si sus propietarios los ofrecieron de manera voluntaria; sí nos consta que, al finalizar la guerra, muchos de ellos estaban inservibles (García Alegre, 1939, 19-20).

${ }_{28}$ Conocemos el nombre de algunos de los colaboradores de la Delegación que actuaron como conductores; por ejemplo, Diego de Quiroga y Losada (1880-1976), XI marqués de Santa María del Villar, quien trabajó para el departamento fotográfico de regiones devastadas durante y con posterioridad a la Guerra Civil española (Sánchez Vigil, 2007); por sus trabajos le fue conferida la Gran Cruz de Isabel la Católica: $A B C$ (Madrid), 5 de enero de 1963, 8. 
A pesar de que la colaboración con la DIDREM fuese desinteresada, no quedó sin recompensa. Tras la puesta en marcha de la prestación del Servicio Social por el Gobierno franquista, en $1938^{29}$, uno de los motivos de exención fue haber prestado servicios por un periodo equivalente al de duración del "Servicio Social" en hospitales de sangre o en instituciones similares ${ }^{30}$; aunque el nombre de la DIDREM no aparece especificado en el texto del decreto, sí lo hace en las notas aparecidas en los diarios en los que se publicitó esta novedad legislativa:

Haber prestado seis meses de servicios gratuitos con anterioridad al 11 de octubre de 1937 en Hospitales de Sangre, obras de asistencia al Frente o instituciones sociales creadas durante la presente guerra (Auxilio Social, Frentes y Hospitales, Hermandad de la Ciudad y el Campo, Cruz Roja, DIDREM, laboratorios y farmacias militares, polvorines, roperos, Subsidio Pro-Combatientes, etc.) ${ }^{31}$.

\section{LAS LABORES DE INFORMACIÓN DOMICILIARIA}

La Memoria... redactada, en 1939, por Manuel Antonio García Alegre recoge, como anexos, los impresos utilizados por la Delegación; tanto aquellos confeccionados cuando el servicio de información estaba circunscrito únicamente a Madrid, como los empleados en los años posteriores, con membrete de Delegación Especial para Información de Residentes en Territorio Liberado. Resultan especialmente interesantes aquellos documentos en los que se recogen las instrucciones de funcionamiento de los servicios de la DIDREM, particularmente de las "oficinas de barrio" y de las emisoras de radio.

Los anexos de la Memoria... final del trabajo realizado por la DIDREM también relatan el modo en que habría de recogerse la información; el modelo se diseñó para la ciudad de Madrid, pero el mismo sistema se instauró en el resto de poblaciones, adaptándolo al tamaño de éstas.

La ciudad de Madrid quedó organizada, a efectos de recopilar información, en veinte sectores y 87 zonas, todas ellas coordinadas por Alejandro Hernández-Sampelayo. Cada grupo de agentes de información, formado por dos personas, tenía a su cargo una de las zonas en que la ciudad se hallaba dividida; debían de recoger, diariamente, un mínimo de sesenta informes sobre los ciudadanos cuyos nombres les eran entregados, al principio de la jornada, por el jefe de sector; se les requería un horario extenso: de 8:00 a 13:00 horas y de 15:00 a 19:00 horas, dedicando las dos horas remanentes a comer (García Alegre, 1939, 75-78).

${ }^{29}$ Decreto 378, de 7 de octubre de 1937. Declarando deber nacional de todas las mujeres españolas, comprendidas en edad de 17 a 35 años, la prestación del "Servicio Social": Boletín Oficial del Estado, 11 de octubre de $1937, \mathrm{n}^{\circ} 356,3785-3787$.

${ }^{30}$ Los otros motivos de exención fueron tener un defecto físico o una enfermedad que impidiese la prestación del servicio y el estado civil: estaban exentas las casadas y las viudas que tuviesen hijos a su cargo.

31 La nota de prensa fue publicada, al menos, en el Diario de Córdoba (Córdoba), 12 de enero de 1938, 2; Heraldo de Zamora (Zamora), 12 de enero de 1938, 3; El Defensor de Córdoba (Córdoba) 10 de enero 1938, 2; El Día de Palencia (Palencia), 13 de enero de 1938, 2; El Avisador Numantino (Soria), 16 de febrero de 1938, 4 y en el periódico falangista Imperio (Zamora), 21 de enero de 1938, 3. 
Los agentes de información se dirigían al último domicilio conocido del ciudadano/a sobre la que la DIDREM había manifestado su interés. Desde la organización se indicaba a los agentes que extremasen su "afabilidad y cortesía" ante las personas a las que iban a interrogar; para ganarse su confianza debían mostrar la tarjeta en la que figuraba el nombre de la persona que había solicitado el informe. Se recomendaba que cada información no se demorase más de diez minutos, incluyendo la firma tanto de la persona que informaba como de los agentes que recogían los datos. Si la persona no sabía firmar, o no quería, los informantes consignaban en la ficha el hecho: "no sabe" o "se niega", respectivamente. Los agentes sólo podían transmitir al interrogado la localización de los Servicios de Beneficencia, Sanidad o de las "oficinas de barrio"; cualquier otra información solicitada les estaba vedada.

Los agentes de información disponían de unos volantes en los que habrían de comunicar, bien a las autoridades de orden público (color azul), bien a las autoridades sanitarias (color blanco), cualquier hecho que considerasen digno de atención (García Alegre, 1939, 81).

No siempre era tarea fácil recabar la información; en muchos casos los edificios estaban destruidos o abandonados, una posibilidad contemplada entre las posibles respuestas que los informantes debían elaborar para cada una de las solicitudes demandadas, las cuales se evacuaban a través de un código ( $c f$. tabla 2 ).

Cada una de las situaciones recogidas en la tabla 2 se correlaciona con un impreso específico; estos estaban destinados a las personas que demandaban información. Además de las trece posibilidades reseñadas, los gestores de la DIDREM disponían de un par más de modelos de tarjetas con mensajes impresos, en las que se señalaba: "No se le encuentra, envíen más datos a las oficinas de Valladolid DIDREM" y "Si no envían más datos para su busca, hemos de considerarlo provisionalmente como desaparecido" (García Alegre, 1939, 91-125).

Como elemento de control del trabajo realizado, los agentes de información cumplimentaban unas hojas de gran formato, donde recopilaban las tareas desarrolladas, organizadas por calles ${ }^{32}$.

Dado el amplio volumen de la correspondencia generado por la DIDREM, se le concedió la franquicia postal; aunque tal situación ya estaba contemplada desde la génesis de la organización ${ }^{33}$, no fue legalizada hasta octubre de $1938^{34}$. La orden de concesión de la franquicia supuso una modificación sustancial en la colección de impresos que hasta entonces habían estado disponibles: se optó por un solo modelo en el que se hacía constar un breve informe acerca de la persona sobre la que se había solicitado el informe; aun cuando en su anverso la organización seguía utilizando las siglas DIDREM, señalando su vincula-

32 Un sistema parecido fue utilizado por el gobierno republicano para controlar a la población madrileña durante la guerra: CDMH, PS-MADRID, carpeta 8, leg. 51; CDMH, PS-MADRID, carpeta 9 leg. 51 ; CDMH, PS-MADRID, carpeta 10, leg. 61. En cada edificio se organizó un "comité de la casa", al que normalmente pertenecía quien ejercía el trabajo de portero, lo que explica el que fueran tantas las personas represaliadas por la dictadura franquista dedicadas a este oficio. El gobierno republicano incluía en las fichas datos sobre si la persona era afecta al régimen republicano o si se sospechaba que era simpatizante de derechas, a qué sindicato pertenecía, la fecha de entrada en la organización y, en su caso, la brigada, batallón o compañía a la que pertenecía.

33 "Ante la próxima conquista de Madrid, un servicio de informaciones urgentes", ABC, Edición Andalucía, 10 de noviembre de 1936, 11.

34 "Orden [13/10/1938] concediendo franquicia postal al Servicio Especial para Información de Residentes en Territorio Liberado”. Boletín Oficial del Estado, 15 de octubre de 1938, n 107, 1824. 
Tabla 2. Clasificación de los resultados obtenidos en las informaciones de los equipos de trabajo de la DIDREM. Elaboración propia a partir de la información recogida en García Alegre, 1939.

\begin{tabular}{|r|l|}
\hline$N^{o}$ & Clasificación de los resultados \\
\hline 1 & Sin novedad. Reside en el domicilio habitual \\
\hline 2 & Sin novedad, pero cambió de domicilio \\
\hline 3 & Sin novedad. Ausente de Madrid \\
\hline 4 & No se le encuentra en las señas que han indicado, pero seguiremos buscando en otras que hemos obtenido \\
\hline 5 & Cuando no se le encuentra y está a la espera de declarársele oficialmente como desaparecido \\
\hline 6 & Se le considera desaparecido, pero seguimos buscando porque las noticias carecen de comprobación \\
\hline 7 & Desaparecido \\
\hline 8 & Ausente de Madrid \\
\hline 9 & Enfermo en su domicilio \\
\hline 10 & Enfermo en el hospital \\
\hline 11 & Herido en domicilio particular \\
\hline 12 & Herido en el hospital \\
\hline 13 & Novedad grave: herido, preso, muerto, evacuado, etc. \\
\hline
\end{tabular}

ción con el Ministerio de Orden Público, en el reverso se identificaba como Delegación Especial para Información de Residentes en Territorios Liberados (figura 3) ${ }^{35}$. En enero de 1939 volvió a modificarse el modelo de tarjeta postal, que se transformaba en "mensaje postal", "con la finalidad de poner rápidamente en comunicación a los españoles residentes en las poblaciones que se liberan con los que residen en el resto de la España Liberada" ${ }^{6}$.

\section{ENTRE EL BLANCO Y EL AZUL: LOS FICHEROS DE LA DIDREM}

Los gestores de la DIDREM dispusieron de dos ficheros diferenciados: el blanco y el azul (figura 1). Por cada solicitud de informe que llegaba a las oficinas de la Delegación se cumplimentaba una ficha destinada a conformar el "fichero blanco", éste llegó a alcanzar la cifra de 214.424 cédulas (García Alegre, 1939, 28-30, 69). Tras recabar la información solicitada, ésta era comunicada a la persona que la había recabado y sus datos se incorporaban a un "fichero azul".

El objetivo del denominado "fichero azul" era, supuestamente, de carácter estadístico. Se trataba de establecer el movimiento poblacional experimentado por cada pueblo o ciudad durante la "dominación roja". La información que conformaba las fichas azules era

35 Jaime Iserte Castillo contaba con tan sólo 18 años de edad cuando ingresó en el campo de concentración de León; hijo de Liberato Iserte y Josefa Castillo, había nacido en Barcelona el 30 de julio de 1920; en el verano de 1951 emigró a Rio de Janeiro (Brasil), a bordo del "Cabo de Hornos"; los datos proceden de su tarjeta de inmigración, conservada en el Arquivo Nacional, Rio de Janeiro: "Brasil, Cartões de Imigração, 1900-1965", https://familysearch.org/ark:/61903/1:1:V13D-F3W, consultado el 13 de febrero de 2016.

36 "Orden de 25 de enero de 1939 autorizando a la Delegación Especial para Información de Residentes en Territorio Liberado el empleo de un nuevo modelo de tarjeta en el uso de la franquicia que tiene concedida”. Boletín Oficial del Estado, 27 de enero de 1939, n 27, 490-491. 

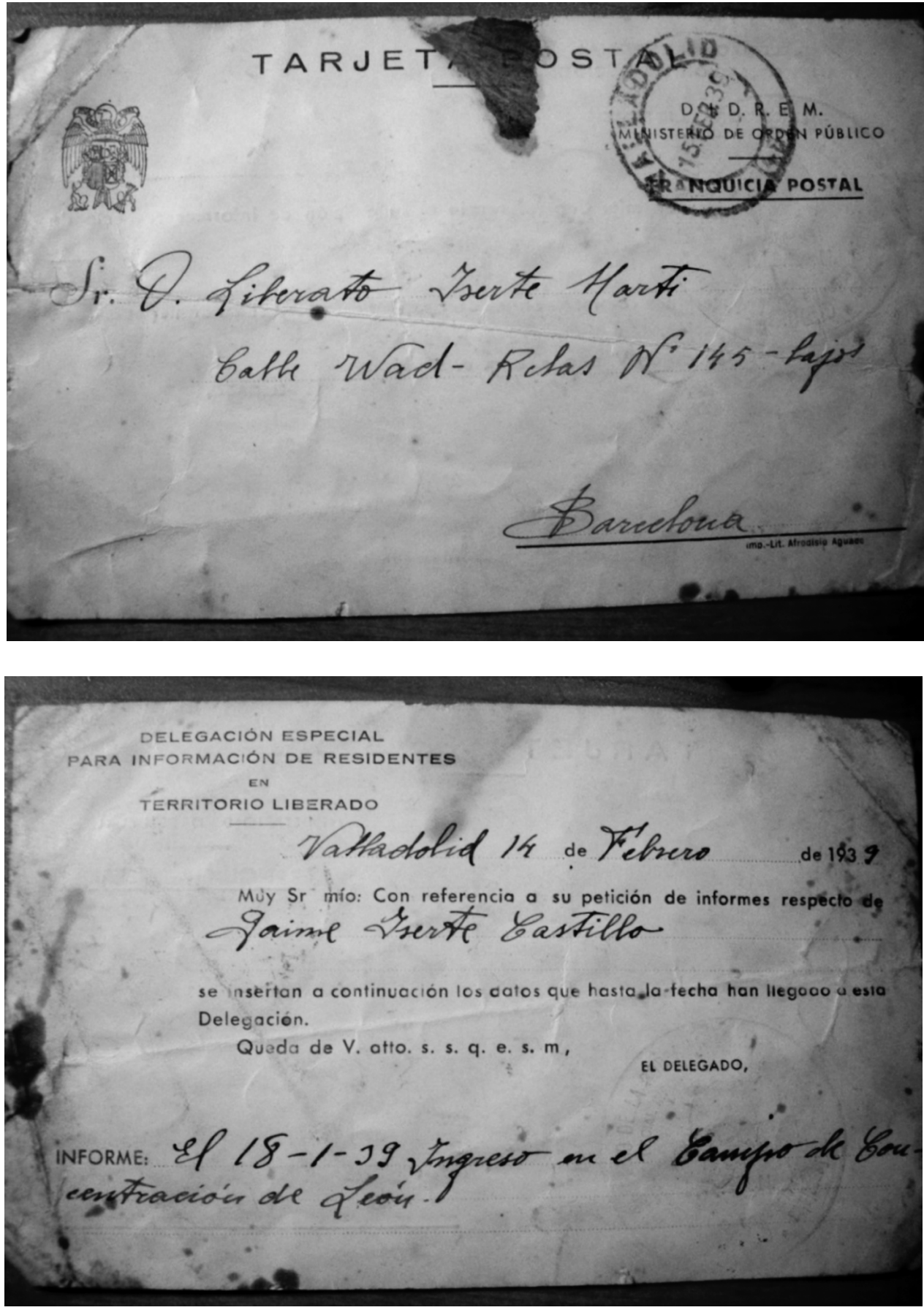

Figura 3. Anverso y reverso de una tarjeta postal en la que consta información personal, emitida por la DIDREM. Valladolid, 14/02/1939. Fuente: Archivo particular [DRB]. 
directamente recogida por los agentes de la DIDREM en los más diversos establecimientos, agrupados en ocho grupos, para los que se establecía una segregación de los equipos informantes en función del sexo (tabla 1). Si la zona era extensa o no se contaba con agentes que pudiesen realizar las tareas de información en persona, la información se solicitaba a los ayuntamientos por telegrama postal (García Alegre, 1939, 137).

En todo momento se intentó enmascarar el funcionamiento de la DIDREM bajo la apariencia de una organización exclusivamente humanitaria. Los datos que se solicitaban a los ayuntamientos, los mismos que se reflejaban en el "fichero azul", nos dan idea de las otras funciones menos "caritativas" de la Delegación. A los alcaldes se les requería que enviasen, a la oficina de la DIDREM, la siguiente información:

$1^{\mathrm{o}}$ Relación de personas asesinadas por los rojos.

$2^{\circ}$ Relación de personas fallecidas por hechos de guerra.

$3^{\circ}$ Relación de las personas encarceladas por los rojos y liberadas por nuestro Glorioso Ejército.

$4^{\circ}$ Relación de las personas encarceladas por los rojos y evacuadas a zona roja.

$5^{\circ}$ Relación de los niños de colegios evacuados a zona roja o al extranjero.

$6^{\circ}$ Relación de las personas más destacadas por su significación izquierdista durante la dominación roja.

No son muchas las respuestas dadas a conocer por los historiadores locales sobre esta petición de la DIDREM; analizaremos dos, ambas de los primeros meses de 1939, tramitadas por los ayuntamientos de Beneixama (Alicante) y Olot (Girona) ${ }^{37}$.

En el caso de Beneixama, el telegrama solicitando la información fue recibido el 18 de abril de 1939 y contestado seis días más tarde; en su informe, probablemente elaborado por el alcalde accidental, Alonso Molla Sans, niega que persona alguna hubiera sido asesinada por "los rojos", no aporta nombre de personas fallecidas por hecho de guerra, e indica el de diecisiete encarcelados por el ejército republicano, tres de ellas "liberados" por el ejército de Franco; tampoco refiere evacuaciones infantiles e incluye un listado de 105 personas (86 hombres y 19 mujeres) "destacadas por su significación izquierdista", ni que decir tiene que muchas de ellas sufrieron represión durante el franquismo (Conca y Guia, 2008, 423-442).

El término municipal de Olot fue ocupado, por las fuerzas del general Alonso Vega, el 7 de febrero de 1939; el telegrama con la solicitud de información, formulada por el "Delegado del Servicio" de la DIDREM al alcalde de Olot, está fechado en Gerona, el 13 de febrero de 1939, en los mismos términos que conocemos para Beneixama, con la salvedad de que en éste se anota una nueva dirección para la respuesta: Paseo de Gracia, 112. Barcelona (Clavijo Ledesma, 2003, 418-419); no nos consta la respuesta que pudiera tener esta solicitud, si es que la hubo.

37 Nos queda constancia de que el Ayuntamiento de Quart del Poblet (Valencia) recibió un telegrama similar de la DIDREM, el 13 de abril de 1939; pero no tenemos más noticias al respecto (Moreno Martín y Olmos Benlloch, 2015, 80). También dio cuenta de él la Hoja Oficial de Tarrasa de 10 de abril de 1939, con un llamamiento final: "No dudamos que por patriotismo y a fin de ayudar a la Justicia de Franco, todos los tarrasenses que puedan aportar algún dato de los solicitados por la D.I.D.R.E.M., acudirá a este llamamiento, ya que a la vez que harán un gran servicio a la Patria, servirán sus manifestaciones para completar la estadística de desmanes ocurridos en esta ciudad durante el funesto período marxista. Tarrasa, 8 de abril de 1939. Año de la Victoria”. 
Tabla 3. Contribución de las distintas oficinas de la DIDREM a la confección del "fichero azul". Elaboración propia a partir de la información recogida en García Alegre, 1939.

\begin{tabular}{|l|c|}
\hline Oficina de la DIDREM & Número de informes \\
\hline Madrid & 25.430 \\
\hline Valladolid & 469.207 \\
\hline Salamanca & 23.700 \\
\hline Málaga & 22.565 \\
\hline San Sebastián & 9.500 \\
\hline Fuenterrabía & 84.756 \\
\hline Bilbao & 71.240 \\
\hline Santander & 33.180 \\
\hline Gijón & 19.104 \\
\hline Zaragoza & 31.656 \\
\hline Cataluña & 135.000 \\
\hline Ávila & 7.186 \\
\hline Murcia-Alicante-Valencia & 10.000 \\
\hline Biarritz & 35.700 \\
\hline Total & $\mathbf{9 7 8 . 2 2 4}$ \\
\hline
\end{tabular}

En las oficinas centrales de la DIDREM, en Valladolid, se recibieron, hasta enero de 1938, la práctica totalidad de la prensa publicada en Madrid, Barcelona, Bilbao y Valencia, así como algunos ejemplares de periódicos franceses, facilitados por el agente de Biarritz. A partir de esa fecha solo se interesaron en la prensa catalana, prestando especial atención a los diarios La Vanguardia y La Solidaridad Obrera.

Todas las "informaciones especiales", procedentes tanto de los equipos locales, como de las contestaciones de los alcaldes de los territorios "liberados", las noticias recogidas en la "prensa roja" y las relaciones de prisioneros en los campos de concentración se incorporaban al "fichero azul" en la oficina central de Valladolid. La tabla 3 recoge la contribución de cada una de las oficinas de la Delegación a la formación de este fichero; ha de tenerse en cuenta que, a fecha de entrega de la Memoria..., en 1939, los informes sobre Madrid apenas estaban iniciados ${ }^{38}$.

De modo que, en 1939, a la fecha de entrega de la Memoria... final elaborada por el delegado de la DIDREM, el "fichero azul" constaba de casi un millón de registros (tabla 3), una cifra muy superior a las 214.424 cédulas del "fichero blanco", el supuesto objetivo principal de la Delegación.

${ }^{38}$ No fueran éstas las únicas que estuvieron en funcionamiento; el periódico Diario Español, impreso en Tarragona, informa, en los inicios de 1939, del nuevo establecimiento de una oficina de la DIDREM en esta localidad: "Delegación Especial para Información de Residentes en Territorio Liberador [sic]. D.I.D.R.E.M. Todas las personas que deseen dar noticias a sus familiares y amigos de la España Nacional pueden pasar por las oficinas de esta Delegación en Tarragona, Rambla de San Juan n ${ }^{\circ} 98,2^{\circ}$, Diario Español (Tarragona), 21 de enero 1939, 3. 
La suma de los dos ficheros elaborados por la DIDREM arroja una cifra de 1.192.648 registros, un número razonablemente parecido al que conformaba el fichero general de la Sección Político Social (Ministerio de la Gobernación) cifrado, en marzo de 1944, en 1.300.000 tarjetas (Espinosa Romero y Rodríguez López, 2015, 140). Aunque la información solicitada por la DIDREM no es demasiado prolija, es posible que fuera el germen de investigaciones posteriores en las que se basó la Causa General impulsada por Eduardo Aunós ${ }^{39}$, un asunto que aún requiere de documentación que lo confirme.

La obsesión del gobierno de Burgos por "fichar" a la población civil fue en aumento durante el transcurso de la guerra, concentrándose las labores de identificación en Valladolid. En octubre de 1937, desde la Secretaría General franquista se redactó el Reglamento y Reglas de Servicio para el Trabajo de los Gabinetes de Fichas en las Fronteras Nacionales de España ${ }^{40}$. Estos Gabinetes tenían la obligación de registrar documentalmente a toda persona, española o extranjera, que entrase en España por las fronteras nacionales terrestres, marítimas, fluviales o aéreas ${ }^{41}$.

Para cada individuo se realizaban dos tipos de fichas diferentes, ambas por duplicado: una copia era custodiada en el Gabinete que la había completado y, la otra, se remitía, diariamente, al Jefe superior de Policía de Valladolid, responsable del Gabinete Central de Identificación. Además de los datos de filiación, se incluía la procedencia inmediata, el punto de salida "de la zona roja", la fecha de la partida, medio de evacuación, lugar de residencia anterior, resumen de su vida en la zona republicana, resumen de su vida en el extranjero, méritos que podrían usarse en su defensa, cuatro nombres de personas que le sirviesen de garantía y el de los familiares que le acompañan. También se le solicitaba información sobre el lugar donde deseaba residir en España, la ocupación a que pensaba dedicarse, profesión, filiación política y residencia habitual. Entre los datos complementarios se debía consignar cualquier marca o cicatriz que pudiese ayudar a identificar a esa persona. En las fichas se incluían las huellas dactilares y, al menos, una fotografía de frente en la que se identificase una tarjeta prendida a la ropa con un número de orden. Aunque el Reglamento y Reglas de Servicio para el Trabajo de los Gabinetes de Fichas en las Fronteras Nacionales de España está fechado en octubre de 1937, ya el 13 de agosto de ese año se había dirigido una circular a todos los Gobiernos Civiles ordenando la puesta en marcha de estos gabinetes de identificación ${ }^{42}$.

39 "Decreto de 26 de abril de 1940, concediendo amplias facultades al Fiscal del Tribunal Supremo para proceder a instruir 'Causa general' en la que se reúnan las pruebas de los hechos delictivos cometidos en todo el territorio nacional durante la dominación roja", Boletín Oficial del Estado, 4 de mayo de 1940, $\mathrm{n}^{\circ} 125,3048-3049$.

${ }^{40}$ AGA (08) 1.5 44/03911.

${ }^{41}$ Se establecieron "Gabinetes de Fichas" en el puente internacional sobre el río Bidasoa, en Irún (Guipúzcoa); en el puente internacional sobre el río Miño, en Tuy (Pontevedra); en la aduana de la estación ferroviaria de Fuentes de Oñoro (Badajoz), en Ayamonte (Huelva), en la aduana de la estación marítima de Algeciras (Cádiz) y en la aduana de La Línea de la Concepción (Cádiz).

${ }^{42}$ AGA (08) 1.5 44/03911. Es fácil apreciar la similitud entre este tipo de registro documental y el que posteriormente constituiría el Documento Nacional de Identidad, de cuya puesta en marcha se hizo cargo Fidel de la Cuerda Fernández, primer responsable de la Jefatura de Servicios Especiales, de la que, a partir de febrero de 1938 y hasta su extinción, pasó a depender la DIDREM. 


\section{LA PROPAGANDA INTERNACIONAL SOBRE LA DELEGACIÓN}

La prensa afín al ideario franquista fue el elemento utilizado para dar publicidad internacional a la DIDREM, a la par que, a través de ella, se reclamaba la difusión de sus servicios; de este modo la Delegación se convertía en un buen elemento propagandístico, no solo dentro del país. Así se manifestaba Gonzalo Queipo de Llano, en una de sus habituales alocuciones radiofónicas, concretamente la transmitida la noche del 21 de noviembre de 1936:

Creada por la Secretaría General del Estado el servicio de información respecto a la situación de los residentes en Madrid, las personas que deseen tal información pueden dirigirse a la oficina establecida en Valladolid, dirección telegráfica y postal DIDREM.

Hay hoy recibidas más de sesenta mil peticiones de informes de Portugal, España y Marruecos, que se contestarán por radio o por correo, cuando sea completa la ocupación de Madrid.

Ni del resto de Europa, ni de Guinea ni América se solicitan informes por desconocimiento, de este servicio; sería interesante que las estaciones que escuchan Sevilla difundan la creación de este servicio para que puedan utilizarlo cuantos tengan familiares en Madrid.

La respuesta se hará por radio, Comunicado Postal o Prensa del país respectivo u otros medios. Cuantas emisoras extracorta y onda normal quieran colaborar en este servicio, pueden dirigirse a DIDREM, en Valladolid, lo cual se ruega ${ }^{43}$.

Lógicamente, la difusión radiofónica de los servicios de la Delegación también tuvo el esperado impacto propagandístico ${ }^{44}$. Las labores de difusión surtieron su efecto y, tan sólo un mes más tarde, a fines de 1936, se empezaron a recibir peticiones de informes desde diversas partes de América, Europa y norte de África; no obstante, la mayoría de las peticiones tenían su origen en el territorio peninsular, siendo Valladolid la provincia que había solicitado mayor número de informes; en los días finales de 1936 la oficina central recibía, de acuerdo con la información aportada por sus gestores, hasta 12.000 fichas diarias ${ }^{45}$.

En los artículos periodísticos sobre la DIDREM publicados por los tórculos afines al franquismo, se hacía hincapié en los fines altruistas de la organización: se publicaban cartas de personas que, supuestamente, habían utilizado el servicio y estaban profundamente agradecidas por "el fin tan humanitario que persiguen", a la par que se intentaba conmover a los lectores, publicando misivas de este cariz:

\section{9.}

43 "La charla radiada anoche por el general Queipo de Llano", $A B C$ (Sevilla), 22 de noviembre de 1936,

${ }^{44}$ De hecho, parece que el uso de la radio como medio de propaganda fue una novedad de la guerra española, ya que durante la Primera Guerra Mundial la radio no se usó con estos fines (Pizarroso Quintero, 1993, 382).

${ }^{45}$ Entre los países solicitantes se encontraban Egipto, Palestina, Argelia, el Marruecos francés, la zona internacional de Tánger, Argentina, Chile, Venezuela, Brasil, Ecuador, Uruguay, Cuba, Alemania, Bélgica, Inglaterra, Suiza, Austria y Hungría. Los países con mayor número de solicitudes cursadas a finales de 1936 eran Portugal, Italia, Francia y algunas naciones sudamericanas: "Nuestra visita a la DIDREM. Una organización magnífica”, $A B C$ (Sevilla), 23 de diciembre de 1936, 10. 
Muy señores nuestros: Reciban las más expresivas gracias de unos niños que, tristes por estar sin noticias de sus papás, deben a ustedes ahora su alegría.- Almudena, Alfonso y Agelines (sic) Donadier ${ }^{46}$.

El mecanismo de actuación de la DIDREM, con respecto a las informaciones solicitadas desde el extranjero, era remitir las cartas al Gabinete Diplomático. Tras la reorganización ministerial franquista, recogida en la ley 30 de enero de $1938^{47}$, las solicitudes se enviaron al Subsecretario de Asuntos Exteriores; éste se ponía en contacto con las representaciones del Gobierno franquista en los diferentes países para hacerles llegar los informes solicitados ${ }^{48}$.

Obviamente, no siempre se recurría a la Delegación para recabar información sobre el estado y paradero de algunas personas; en ocasiones las pesquisas se formulaban ante instancias superiores; el Gobernador General del Estado, Luis Valdés Cabanillas, recibió a primeros de diciembre de 1936, una solicitud procedente del "representante del Gobierno Nacional en Bruselas", recabando informes de Luis Herrero, propietario del viñedo "Vega Sicilia", en Quintanilla de Abajo (Valladolid); la demandante de la información, su propia esposa, se encontraba en Bruselas. La información fue tramitada a través de la Jefatura Superior de Policía y Orden Público ${ }^{49}$.

Las informaciones requeridas por los gestores de la DIDREM iban, en ocasiones, más allá de la localización del sujeto; por ejemplo, el 30 de noviembre de 1937 se requirieron "cuantos detalles le sean posibles" sobre la muerte violenta de un matrimonio acaecida en Barcelona ${ }^{50}$; en otros casos, la petición de información se refería a inmuebles y no a personas, tal la relativa al estado de la "Casa Molin" en el número 14 de la calle Arranegi, en Lekeitio (Vizcaya) ${ }^{51}$.

\section{A MODO DE EJEMPLO: EL CASO DE CINTA FONT MARGALEF}

Cinta Font Margalef (1907-1986) fue una de las matronas que hubo de exiliarse al finalizar la Guerra Civil (Ruiz-Berdún y Gomis, 2012, 221-238); nacida en Benissanet (Tarra-

46 "Nuestra visita a la DIDREM. Una organización magnífica", el artículo original fue publicado en las páginas de El Norte de Castilla, un periódico editado en Valladolid, correspondientes al 18 de diciembre de 1936 y, desde él, reimpreso por una amplia panoplia de la prensa franquista: $A B C$ (Sevilla), 23 de diciembre de 1936, 10; Odiel (Huelva), 24 de diciembre de 1936, 2; La Prensa (Santa Cruz de Tenerife), 8 de enero de 1937. No ha de extrañar pues, como refiere el cronista de La Prensa, el suelto iba acompañado de una nota oficial: "El Delegado especial del Excmo. Señor secretario general de Su Excelencia el Jefe del Estado, para información de residentes en Madrid, remite al Excmo. señor Gobernador general la siguiente información...".

47 Ley organizando la Administración Central del Estado, Boletín Oficial del Estado, 31 de enero de $1938, \mathrm{n}^{\circ} 467,5514-5515$.

48 MECD, AGA (10) 000 82/02587.

49 MECD, AGA (08) 1.5 44/03911. En enero de 1938 se conoce el organismo como Jefatura Superior de Seguridad Interior, Orden Público e Inspección de Fronteras.

${ }^{50}$ El matrimonio lo componían Germán Puig y Mee Angalsell, estaba domiciliado en la Avenida de la República Argentina 17 (Barcelona): MECD, AGA, (10) 000 82/02587.

51 Al parecer, en el momento de redactar el informe, el inmueble se encontraba en perfectas condiciones, pero no se pronosticaba un buen futuro al encontrarse ubicado dentro del radio de acción de la artillería: MECD, AGA, (10) 000 82/02587. 
gona), llegó a México en el barco Nyassa, el 16 de octubre de 1942, junto a su marido, el escritor Artur Bladé i Desumvila (1907-1995), con quien había contraído matrimonio el 10 de junio de 1931 (Riera Llorca, 1994, 272; Sabaté Casellas y Pérez Abadía, 2008, 300). Durante la guerra desempeñó el puesto de Jefa interina de servicio del Establecimiento Correccional de Mujeres de Barcelona ${ }^{52}$; su marido ejerció como secretario de Martí Rouret i Ca1lol, Consejero de Sanidad y Asistencia Social del Gobierno de la Generalitat formado por Lluís Companys i Jovernota entre julio y septiembre de 1936 y, más tarde, como Comisario de Orden Público y Subsecretario de la presidencia de la Generalitat de Cataluña (Bladé i Desumvila, 1976, 13-14). Artur Bladé, que había colaborado como practicante en diversos hospitales de sangre durante el conflicto bélico, cruzó la frontera con Francia el 8 de febrero de 1939, mientras que Cinta Font y su hijo permanecían en Barcelona (Ruiz-Berdún y Bladé i Font, 2016).

Tras la entrada de las tropas franquistas en la Ciudad Condal, Cinta Font empezó a recibir las insistentes visitas de dos individuos, uno de ellos paisano de Benissanet, interesados en conocer el paradero de Artur Bladé. Al principio por desconocimiento y finalmente por desconfianza, nunca comentó con sus visitantes datos relativos a su marido; la situación de agobio y la inseguridad que le producían estas inspecciones le llevaron a iniciar el camino del exilio hacia Francia ${ }^{53}$. El 14 de junio de 1939 cruzó la frontera con el país vecino acompañada de su pequeño hijo Artur. No pudo tomar la decisión en mejor momento; entre la documentación procedente del Ayuntamiento de Benissanet, conservada en el Arxiu Comarcal de la Ribera d'Ebre, se encuentra un informe de la DIDREM, fechado el 14 de junio de 1939, donde constan los nombres de los empleados municipales, entre ellos el de la comadrona Cinta Font Margalef quien "Por tratarse de persona peligrosísima se halla sujeta a expediente depuración" (figura 4). El 15 de junio la policía se presentaba en su casa para detenerla; había huido hacia Francia el día anterior.

Está claro que los objetivos de las informaciones conseguidas por la Delegación iban más allá de los fines "caritativos" con los que en todo momento ésta intentó presentarse.

\section{EL FINAL DE LA GUERRA}

Tras la entrada de las tropas franquistas en Madrid, las oficinas centrales de la DIDREM se trasladaron desde Valladolid a la capital, instalándose inicialmente en la calle Jorge Juan 23; posteriormente sus oficinas se ubicaron en el Paseo del Prado $6^{54}$, donde siguieron funcionando en los primeros meses de la postguerra ${ }^{55}$.

La Memoria... redactada por Manuel Antonio García Alegre llevaba la significativa fecha de 18 de julio de 1939, estaba dirigida a Ramón Serrano Suñer, Ministro de la Gobernación. En su carta de presentación, además de agradecer la confianza depositada en él, el de-

52 Orden de 13 de febrero de 1937, firmada por Rafael Vidiella, Conseller de Justicia, Diari Oficial de la Generalitat de Catalunya, 21 de febrero de 1937, n 52, 827 (Navarro, 2009, 158).

${ }^{53}$ No era ésta la primera vez; había intentado huir antes de que las tropas franquistas entraran en Barcelona, pero el caos producido por los bombardeos de la aviación sobre Barcelona y Badalona le impidió conseguir su objetivo (Bladé i Desumvila, 1976, 161-185).

54 "Traslado de oficina", $A B C$ (Madrid), 18 de junio de 1939, 1.

55 "Ministerio de la Gobernación. Información sobre residentes en territorio liberado", $A B C$ (Madrid), 6 de julio de 1939, 9. 


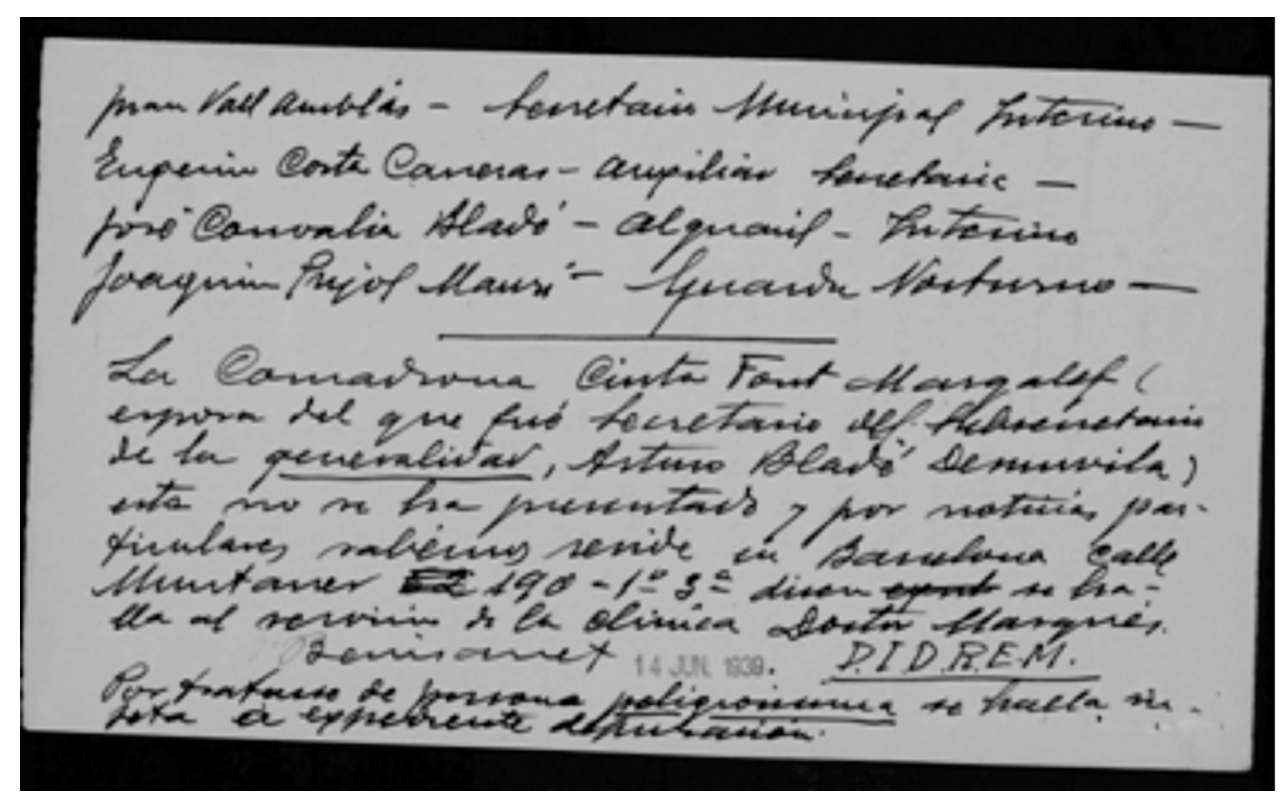

Figura 4. Información sobre Cinta Font Margalef, sometida a expediente de depuración. Arxiu Comarcal de la Ribera d'Ebre. Fuente: https://familysearch.org. La imagen forma parte (imágenes 3637) de la captura de documentación realizada, en el Arxiu Comarcal de Ribera d'Ebre, por la Genealogical Society of Utah, en 2012, bajo el título "Spain, Cataluña, Tarragona, Ribera de Ebro, Benissanet, registros militares".

legado sugería la necesidad de adoptar un acuerdo ministerial, bien para dar continuidad a sus trabajos, bien para decidir qué organismo del Estado debía "centralizar toda esta clase de informaciones, antes de disolver la Secretaría general de la Delegación y de liquidar esta".

La DIDREM no siguió en funcionamiento mucho más allá del mes de julio de 1939. Sin embargo, las informaciones obtenidas por la Delegación Especial para la Información de Residentes en Territorio Liberado, como hemos podido comprobar en el caso de Cinta Font Margalef, fueron utilizadas con fines represores, antecediendo a otras instituciones que habrían de ocuparse de ello en los primeros años del franquismo, tal como la Oficina de Información y Propaganda Anticomunista (OIPA) o la Delegación de Estado para la Recuperación de Documentos.

Una de las conclusiones fundamentales de esta investigación es que, si bien inicialmente la DIDREM pudo ser concebida con propósitos meramente propagandísticos, tanto el desarrollo de la guerra, como el descubrimiento de su utilidad potencial en labores de información, fueron modificando sus cometidos a lo largo de la contienda. Este cambio de orientación queda claramente definido con su adscripción a la Delegación de Servicios Especiales. De los documentos localizados se deduce que la organización debió contar con un número mayor de colaboradores de los que aparecen en la Memoria... analizada en este artículo. 
También es evidente la vinculación de la organización, tanto con las jerarquías eclesiásticas, como con las agrupaciones católicas, que tal vez buscaban una manera de participar en la guerra de una forma menos pasiva que cuidando a las víctimas. Pero quedan muchas cuestiones sin contestar, como el porqué de dicha relación, o cómo se articulaba su funcionamiento con otras organizaciones como la Falange o el resto de servicios especiales y represores del gobierno franquista.

El mayor interrogante que plantea este estudio es cuál fue el destino de la ingente documentación producida por la DIDREM después de la guerra. El hecho de que apenas exista bibliografía sobre la organización podría indicar que fue destruida, bien desde el principio o, lo que sería más probable, después de haber sido vaciado su contenido en otro tipo de ficheros utilizados tras la guerra con fines represores. Este estudio también es una demostración de que, a pesar de la abundantísima producción historiográfica relativa a la Guerra Civil, todavía existen numerosos interrogantes sobre lo sucedido en aquellos años tan tristes y tan terribles para la historia del país. Interrogantes que posiblemente abran el camino a nuevas líneas de investigación.

\section{BIBLIOGRAFÍA}

ALFAYA CAMACHO, José Luis (1988): "La diócesis de Madrid-Alcalá durante la Guerra Civil: 1936-1939", Excerpta e dissertationibus in Sacra Theologia, 15, 499-580.

ANDRÉS-GALLEGO, José y PAZOS, Antón M., eds. (2002): Archivo Gomá: documentos de la Guerra Civil, Tomo 3: Febrero 1937, Madrid, Consejo Superior de Investigaciones Científicas, 400 p.

BLADÉ I DESUMVILA, Artur (1976): L'exiliada (Dietari de l'exili, 1939-1940), Barcelona, Editorial Pòrtic, $537 \mathrm{p}$.

BLANCO VALDÉS, Juan L. (2003): “A Estrada, 18 de xullo de 1936, dous testemuños”, A Estrada: Miscelánea histórica e cultural, 6, 105-124.

CENARRO, Ángela (2002): "Matar, vigilar y delatar: la quiebra de la sociedad civil durante la guerra y la postguerra en España (1936-1948)", Historia Social, 44, 65-86.

CERVERA GIL, Javier (1998): "La radio: una arma más de la Guerra Civil en Madrid", Historia y Comunicación Social, 3, 263-293.

CLAVIJO LEDESMA, Julio (2003): La política sobre la població refugiada durant la Guerra Civil: 1936-1939, Tesis doctoral, Girona, Universitat de Girona.

CONCA, Maria y GUIA, Josep (2008): "Aportaciones al estudio de la represión franquista en Beneixama (1939-46). Transmisión oral y documentación escrita", Cahiers de Prohemio, 10, 423-442.

CONDE MORA, Francisco Glicerio (2008): $D^{a}$ María de Madariaga y Alonso (1905-2001), Cádiz, Salus Infirmorum, $114 \mathrm{p}$.

ESPINOSA ROMERO, Jesús y RODRÍGUEZ LÓPEZ, Sofía (2015): "El Archivo de la Guerra Civil de Salamanca. De la campaña a la transición”, en Galende Díaz, Juan Carlos y Cabezas Fontanilla, Susana (dir.), Paseo documental por el Madrid de antaño, Madrid, Universidad Complutense de Madrid, 131-155.

FERNÁNDEZ CASTRO, Juan Andrés (2004): “Alén da saudade: a fotografía como documento histórico", A Estrada: Miscelánea histórica e cultural, 7, 229-333.

GARCÍA ALEGRE, Manuel Antonio (1939): Memoria de la actuación de la Delegación para el Servicio de Información de Residentes en Territorio Liberado (DIDREM), Madrid, Gráficas de Afrodisio Aguado, $181 \mathrm{p}$.

GONZÁLEZ QUINTANA, Antonio (1994): "Fuentes para el estudio de la represión franquista en el Archivo Histórico Nacional, sección 'Guerra Civil'”, Espacio, tiempo y forma, Serie V, Historia Contemporánea, 7, 479-508. 
GONZÁLEZ SEGURA, Andrés A. (2008): "Las publicaciones periódicas de la Juventud Masculina de Acción Católica en España (1923-1939)", Anales de Historia Contemporánea, 24, 333-359.

HERNÁNDEZ GONZÁLEZ, Martín (1935): Manual del radioescucha: Nociones de electricidad y radiotelefonía, Valladolid, Imprenta Castellana, $246 \mathrm{p}$.

HERRERA HERMOSILLA, Juan Carlos (2012): Breve historia del... espionaje, Madrid, Ediciones Nowtilus, $304 \mathrm{p}$.

JEREZ MIR, Miguel (1982): Élites políticas y centros de extracción en España, 1938-1957, Madrid, Centro de Investigaciones Sociológicas, 499 p.

MARÍN CORBERA, Martí (2010): "La gestación del Documento Nacional de Identidad: un proyecto de control totalitario para la España franquista", en Navajas Zubeldía, Carlos e Iturriaga Barco, Diego (eds.), Novísima. Actas del II Congreso Internacional de Historia de Nuestro Tiempo, Logroño, Universidad de la Rioja, 323-338.

MORENO MARTÍN, Andrea y OLMOS BENLLOCH, Pau (2015): Quart de Poblet 1936-1939: Un poble de la rereguarda, Quart de Poblet, Ajuntament de Quart de Poblet, 251 p.

MORENO SECO, Mónica (2003): "De la caridad al compromiso: las mujeres de Acción Católica (1958-1968)", Historia Contemporánea, 26, 239-265.

NAVARRO, Natàlia (2009): "La inserció de les dones a la vida pública i política durant la Segona República (1931-1939)", Eines, per a l'Esquerra Nacional, 9, 151-161.

NEGRÍN FAJARDO, Olegario (2006): "La depuración franquista del profesorado en los institutos de segunda enseñanza de España (1937-1943). Estudio cuantitativo para Galicia”, Sarmiento. Anuario Galego de Ciencias da Educación, 10, 59-99.

PAREJO FERNÁNDEZ, José Antonio (2011): "Fascismo rural, control social y colaboración ciudadana. Datos y propuestas para el caso español", Historia Social, 71, 143-159.

PÉREZ-OLIVARES GARCÍA, Alejandro (2015): "Objetivo Madrid: planes de ocupación y concepción del orden público durante la Guerra Civil española", Culture \& History Digital Journal, 4: e019. doi: 10.3989/chdj.2015.019.

PIZARROSO QUINTERO, Alejandro (1993): Historia de la propaganda: notas para un estudio de la propaganda política y de guerra, Madrid, Eudema, 480 p.

PRESTON, Paul (2013): El holocausto español. Odio y exterminio en la Guerra Civil y después, Barcelona, Debolsillo, $864 \mathrm{p}$.

RIERA LLORCA, Vicenç (1994): Els Exiliats Catalans a Mèxic, Barcelona, Edicions Curial, 384 p. RUIZ-BERDÚN, Dolores y GOMIS, Alberto (2012): "Las matronas españolas en el exilio", Quipu. Revista Latinoamericana de Historia de la Ciencia y la Tecnología, 14 (2), 231-238.

RUIZ-BERDÚN, Dolores (2015): "Matronas y enfermeras a pie de guerra: la invisibilidad del trabajo sanitario femenino durante la Guerra Civil (1936-1939)", en González Redondo, Francisco A. (coord.), Ciencia y Técnica entre la paz y la guerra, 1714, 1814, 1914, Vol. 1 [en línea], Sociedad Española de Historia de las Ciencias y de las Técnicas, 2015: 523-530. Disponible en: https://drive.google.com/file/d/0B78MGHYEEe2TenNTeXB0MVB0RU0/view

RUIZ-BERDÚN, Dolores y BLADÉ I FONT, Artur (2016): "Una matrona en el exilio republicano: Cinta Font Margalef", Medicina e Historia, 36, 16-26. Disponible en: https://issuu.com/funda cionuriach/docs/mh_3_2016

SABATÉ CASELLAS, Ferran y PÉREZ ABADÍA, Concepción (2008): "Contribució al coneixement de l'exili sanitari femení de 1939, des dels Països Catalans a Amèrica", Gimbernat, 50, 299-305.

SÁNCHEZ VIGIL, Juan Miguel (2007): Del daguerrotipo a la Instamátic: Autores, tendencias, instituciones, Gijón, Ediciones Trea, 206 p.

SERRANO GARCÍA, Rafael (2005): "El Círculo de Recreo de Valladolid. La sociabilidad elitista en Castilla entre la Segunda República y el primer franquismo", Mélanges de la Casa de Velázquez, 35/1, 255-273.

SILVA TAPIA, Miguel (2007): "La Juventud de Acción Católica Española. La revista La Flecha (1932-1936)", Anuario de Historia de la Iglesia, 16, 453-457.

THOMAS, Hugh (1976): La Guerra Civil Española, vol. 2, Barcelona, Ediciones Grijalbo, 666 p. 